\title{
ELECTROSLAG WELDING OF LARGE-SIZED PRESS FRAME
}

\author{
K.P. SHAPOVALOV ${ }^{1}$, V.A. BELINSKY ${ }^{1}$, A.E. MERZLYAKOV ${ }^{1}$, S.N. KOSINOV ${ }^{1}$, \\ K.A. YUSHCHENKO' ${ }^{2}$, I.I. LYCHKO ${ }^{2}$ and S.M. KOZULIN ${ }^{2}$ \\ ${ }^{1}$ Company «Novo-Kramatorsk Machine-Building Works» \\ 5 Ordzhonikidze Str., 847305, Kramatorsk, Ukraine. E-mail: ztm@nkmz.donetsk.ua \\ ${ }^{2}$ E.O. Paton Electric Welding Institute, NASU \\ 11 Kazimir Malevich Str., 03680, Kiev, Ukraine. E-mail: office@paton.kiev.ua
}

\begin{abstract}
The first in the world practice experience of production of the welded-forged structure of the lower frame of 70/90 MN forging press with thickness of welded butts in the range of 3000-3800 mm was described. The total weight of the structure amounted to 160-200 t. During manufacture the technology of electroslag welding using consumable nozzle was used. The role of the fixture belonged to the closed box-like shape of the welded billets themselves with stiffeners. The welded billet was subjected to normalizing with tempering and ultrasonic testing. The gained experience in producing welds of super-large cross sections can be used in development of methods for calculation of expected deformations and technical procedures of their control. 8 Ref., 4 Figures.
\end{abstract}

Ke y w or d s : electroslag welding, press-forging equipment, welded-forged structure, press lower frames, super-large cross sections, specifics of production
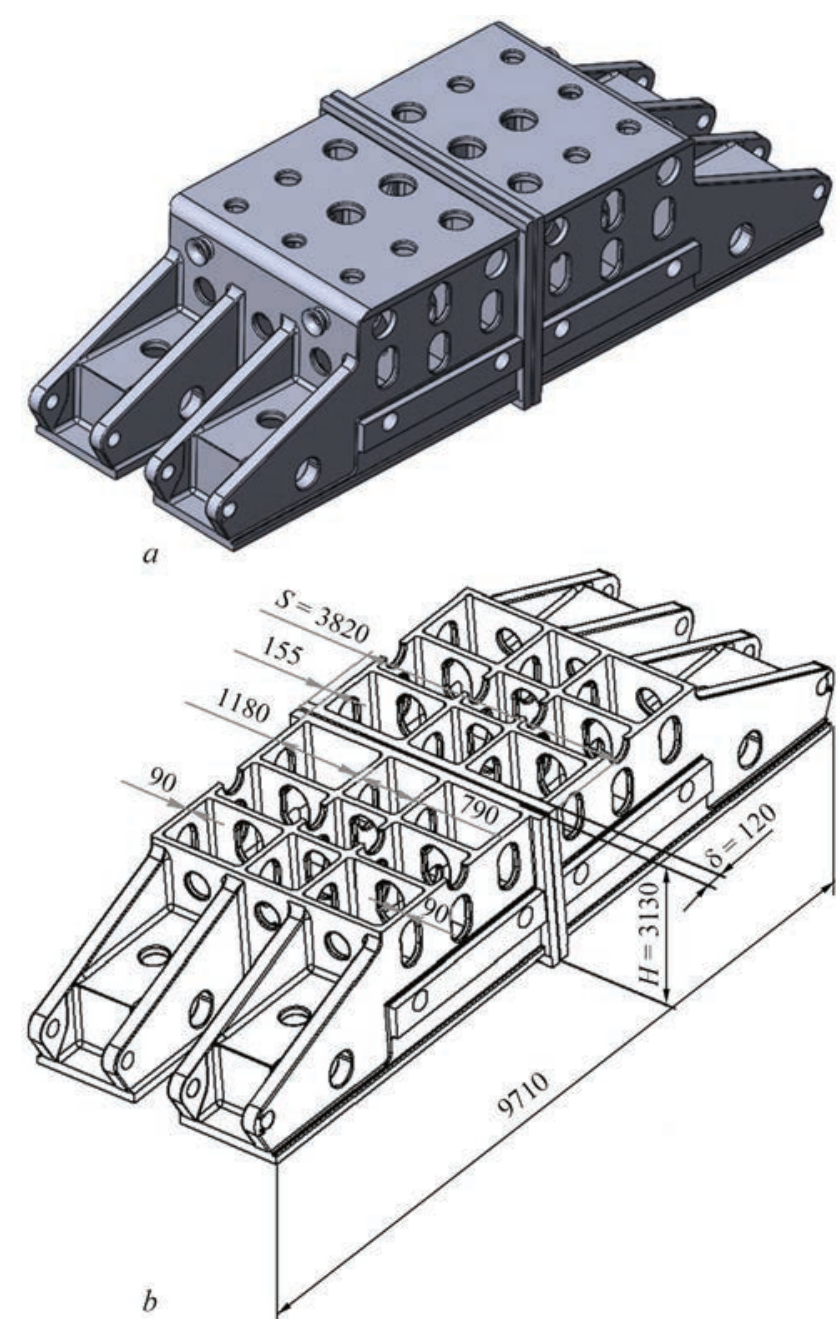

Figure 1. General view (a) and schematic diagram $(b)$ of middle part of frame of forging hydraulic press with force of 70/90 MN
Over more than 60 years the Novo-Kramatorsk Machine-Building Works (NKMZ Company) produces different press-forging equipment, where almost all the load-carrying elements are produced in welded-cast or welded-forged variants applying electroslag welding (ESW). During that period more than 300 units of powerful press-forging machines were manufactured and delivered, which today are successfully operated in more than 20 countries around the world. At present the production of forging hydraulic presses with the force of more than $30 \mathrm{MN}$ is an important challenging direction of the heavy engineering.

One of the basic elements of such presses is a lower frame, the middle beam of which (Figure 1, $a$ ) is manufactured of steel $30 \mathrm{~L}$ in the welded-cast variant (total weight is 160-200 t, thickness of butts being welded is within the ranges of $S=3000-3800 \mathrm{~mm}$ ). Thus, for example, the middle beam of the lower frame of the forging press with force of 70/90 MN represents a three-dimensional box-type structure of $200 \mathrm{t}$ consisting of two cast billets, joined using electroslag welding with consumable nozzle (ESW CN). The cross section of the welded butt $(S \times H)$ has dimensions of $3820 \times 3130 \mathrm{~mm}$ (Figure $1, b$ ).

It should be noted that until now in the world practice of welding production the examples of welding of steel billets of such a cross section of the weld were not known. Furthermore, the structure of the middle beam differs from the typically widespread massive billets with a large thickness of the weld so 
that the wall thickness of edges being welded is only $\delta=120 \mathrm{~mm}$ (see Figure 1, $b$ ).

For ESW CN of rigid billets (the width of welded elements $\delta$ is not smaller than the weld thickness $S$ ), the value and character of the expected displacements of the edges being welded along the length of the weld $H$ and the change in value of welding gap above the slag pool can be predicted with a fair degree of accuracy $[1,2]$. The conditions of ESW CN of flexible plates, where the ratio of weld thickness to width of the plate is larger than one $(S / \delta>1)$, were almost not investigated. Therefore, it is rather difficult to determine the conditions of fixing (assembly) of parts being welded, which provide the expected value, and the nature of welding deformations within the permissible limits as well as the gap value throughout the whole welding process.

The analysis of temperature-time conditions of heat energy spreading and weld formation in ESW of large-thickness metal $[3,4]$ shows that during welding of relatively thin plates it is impossible to determine the nature of displacement of edges being welded in the course of producing weld beforehand. Here either the excessive decrease in the gap is possible which may cause a short-circuiting between the edges and consumable nozzles, or, vice versa, the increase in the gap value at which the edges can come out beyond the limits of forming devices. The both are inadmissible as far as it will result in interruption of the welding process. The nature of influence of mode parameters and methods of external influence on welded edges, which could provide the gap value and geometrical parameters of flexible plates within the acceptable limits, are also unknown. To limit the movement of edges being welded in arc welding all kinds of devices (jigs, cramps, etc.) are often used. Because of large dimensions of billets, significant masses and volumes of the simultaneously crystallized weld metal as well as small width of welded edges, it is practically impossible to use these methods in the case of ESW.

In ESW CN of the middle beam of the lower frame the role of the jig (fixture) belonged to a closed boxlike shape of the welded billets themselves, where the stiffeners located perpendicularly to the plane of the welded edges (see Figure 1,b) prevent change in the gap size if it is higher than the permissible limits over the butt height. Regarding the shape of the gap across the weld thickness in the intervals between the stiffeners, at the level of maximum penetration some buckling of welded edges can be expected. However their value should be negligible due to a relatively slow heating of edges metal across the whole thickness to $500-600{ }^{\circ} \mathrm{C}$ (thermoplastic state) and due to the effect of crystallizing weld, moving behind the zone of maximum heating of edges at distance of $15-30 \mathrm{~mm}$ at the speed of welding.

The technology and methods for assembly of massive billets of large dimensions and thickness of edges being welded, typically applied at the plant for ESW $\mathrm{CN}$, include the following operations: assembly of

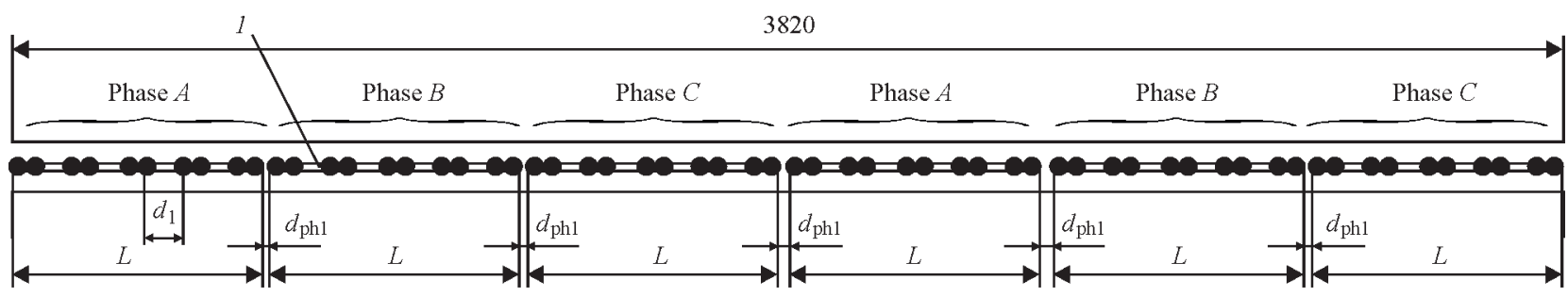

$a$

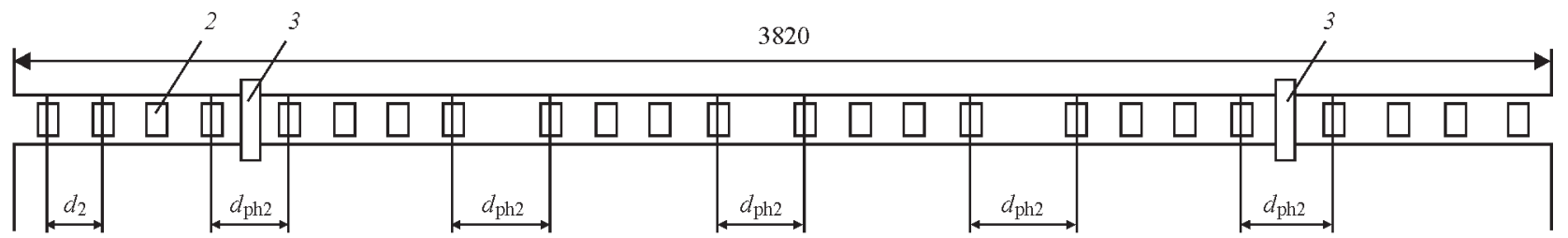

$b$

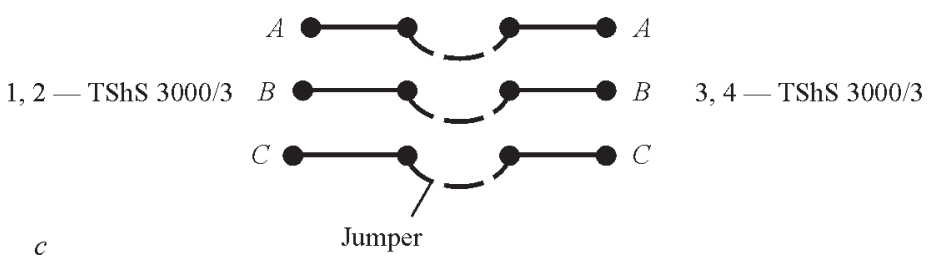

Figure 2. Schemes of mounting the nozzle plates in gap $(a)$, cramps for mounting the consumable nozzles $(b)$ and joining the phases for four power sources $(c)$ : 1 - section of consumable nozzle; 2 - cramps for sections fastening; 3 - cramp-jumper; $L-$ width of one section (phase) of consumable nozzle; $d_{1}$ - distance between the axes of channels guiding; $d_{\text {ph1 }}$ - distance (interphase) between the consumable nozzles; $d_{2}$ — distance between the cramps for sections fastening; $d_{\mathrm{ph} 2}$ - interphase distance for cramps 


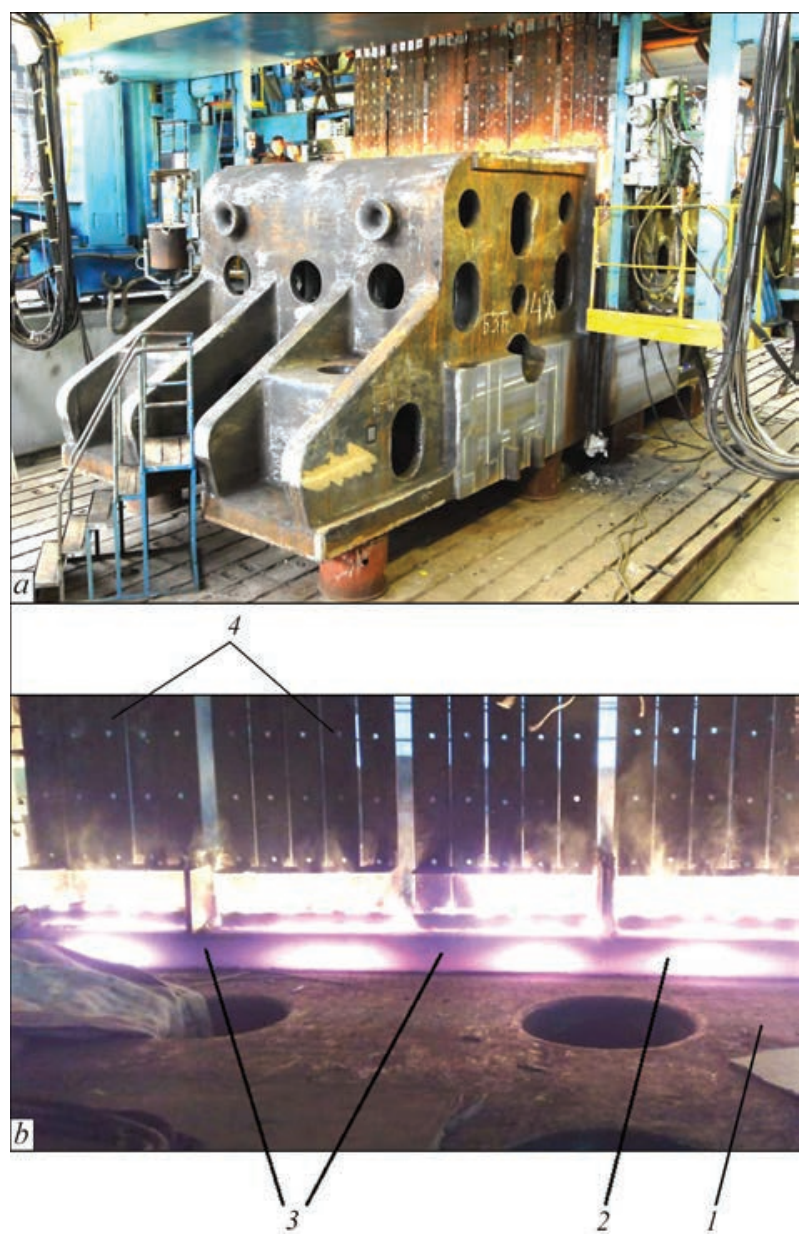

Figure 3. ESW of middle part of the frame (a) and heating of runout straps in a few minutes before termination of welding process (b): 1 - billet; 2, 3 - heating of back side of the edges at places corresponding to groups of nozzles and interphase gaps; 4 - consumable nozzles

welded billets between each other at a definite assembly gap, which is fixed by assembly straps [5]; placing the installation for ESW with a consumable nozzle, assembled for welding billet, to the pit-type stand [6]; running of the installation on the assembled part; wheeling out of the trolley with welding machines to the extreme position; placing of consumable nozzles attached in the clamps of machine ASh-110 into the gap one after another. Further the preparatory works

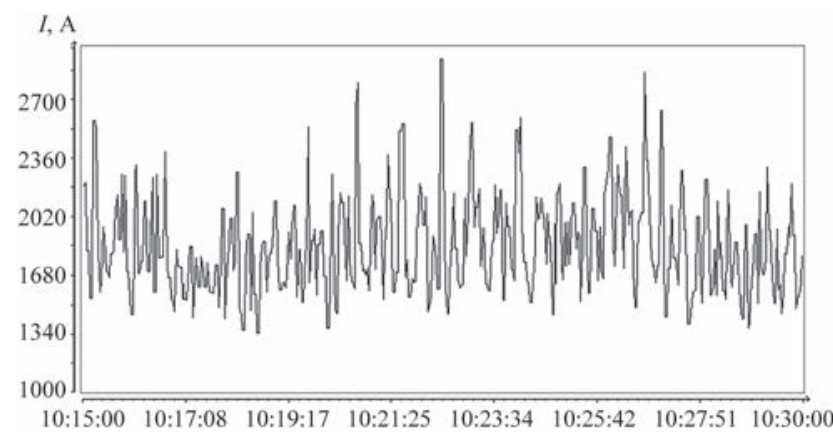

Figure 4. Oscillogram of welding current (process duration of 15 min, phase $A$, transformers 1, 2 (see Figure 2,c) are carried out: alignment of nozzles in the gap, running of wire in the tubes of nozzles, etc.

Due to the large dimensions of the structure of the middle beam of the lower frame the technology of its assembly differed from the standard one. Initially one half of the beam was placed to the pit stand. The cramps are welded-on to the initial straps of the billet and the plate of rolled steel is placed on them, forming the «bottom of the pocket». Then, the installation runs over the fixed billet and the consumable nozzles are fastened to the clamps of the welding machines ASh110: 24 plates of consumable nozzles, divided into 6 groups of 4 plates each (Figure 2). After mounting of all the nozzles, their position was fixed relatively to the billet by means of welded-on cramps for sections fastening (Figure 2, $b$, pos. 2) and then the plates were released from clamps of welding machines. To setting the second half of the middle beam of the lower frame the installation is moved to the extreme position. The assembly gap is formed as follows: $36 \mathrm{~mm}$ at the bottom and $40 \mathrm{~mm}$ at the top of the butt. After assembly of the parts to be welded with the specified gap, the «bottom of the pocket» is tightly pressed to the initial straps of the assembled part by means of jacks. Then the installation runs over the assembled billet and the consumable nozzles are fastened again in the clamps of welding machines, and the fixing cramps are cut off.

The weld on both sides was formed by means of shoes (Figure 3,a). The assembly gap at the level of run-out straps is fixed with two cramps - jumpers (see Figure 2, b, pos. 3) welded-on to the running out straps using electric arc welding. The cramps-jumpers are positioned between the first, the second, and between the fifth and the sixth groups of nozzles (see Figure $2, b)$. The electroslag process started with the «liquid start». During welding the monitoring of basic parameters of welding mode was carried out [7, 8] (Figure 4). In addition, in the course of welding the required depth of the slag pool on both sides of the weld was regularly controlled and maintained, and also the heating of the back side of welded edges was monitored. It should be noted that the heating temperature of the back side of edges from the moment when the weld came beyond the input pocket (in the gaps between the stiffeners) was $550-650{ }^{\circ} \mathrm{C}$, and it increased to $900-1100{ }^{\circ} \mathrm{C}$ only when the slag pool approached the distance of $250-300 \mathrm{~mm}$ before the output pocket (see Figure $3, b$ ).

The slight increase in the gap between the edges above the mirror of the slag pool was fixed at the level of $1200 \mathrm{~mm}$ of the weld, i.e. $42-43 \mathrm{~mm}$. The increase in the gap became more pronounced after welding of half of the weld (the detachment of both cramps-jumpers occurred (see Figure 2, $b$, pos. 3), the gap on the 
running out straps amounted to $50 \mathrm{~mm}$. During approach of the slag pool to the level of $2500 \mathrm{~mm}$ from the beginning, the opening of the gap near the shoes reached the value of $55 \mathrm{~mm}$ and did not change any more. The short circuits between the nozzles and the edges during welding were not recorded. The whole welding process was carried out without violation of the preset parameters of the mode and the methods of weld production. Then the welded billet of the middle beam was subjected to normalizing with tempering and after ultrasonic testing it was sent to the further mechanical treatment.

Thus, for the first time in the world practice of welding ESW CN production the weld of super-large cross section of $11.96 \cdot 10^{3} \mathrm{~mm}^{2}(S=3820 \mathrm{~mm}$ at $\delta=120 \mathrm{~mm}$ ) was produced.

The experience of producing welds of super-large cross sections produced using electroslag welding with consumable nozzle for joining the flexible plates should be used in the development of scientifically grounded methods for calculation of the expected deformations and technical procedures of their control.
In the recent years the enterprise manufactured and delivered six hydraulic forging presses with capacity of 60-100 MN to South Korea, China, Japan and India. The basic load-carrying elements of those presses were produced with applying the ESW CN technologies described above.

1. (1980) Electroslag welding and surfacing. Ed. by B.E. Paton. Moscow: Mashinostroenie.

2. Sushchuk-Slyusarenko, I.I. (1969) Method of obtaining of accurate sizes in electroslag welding. Kiev: UkrNIINTI.

3. Vinokurov, V.A. (1968) Welding strains and stresses. Moscow: Mashinostroenie.

4. Makhnenko, V.I. (1976) Computational methods for investigation of kinetics of welding stresses and strains. Kiev: Naukova Dumka.

5. Sushchuk-Slyusarenko, I.I., Lychko, I.I. (1974) Procedure of performance of electroslag welding. Kiev: Naukova Dumka.

6. Nevidomsky, V.A., Krasilnikov, S.G., Panin, A.D. et al. (2002) New machine for electroslag welding of large parts at JSC «NKMBF». The Paton Welding J., 2, 49-51.

7. Voloshin, A.I., Shapovalov, K.P., Belinsky, V.A. et al. (2012) Method for manufacture of large-sized forged-cast billets using electroslag welding. Ibid., 5, 43-45.

8. Litvinenko, S.N., Shapovalov, K.P., Kosinov, S.N. et al. (2013) Systems of process control and monitoring of conditions - the important factors of quality assurance in electroslag welding of thick metal. Ibid., 12, 39-41.

Received 03.03.2016 